\title{
LAS OBRAS DE REFORMA DEL ESTADIO CARLOS TARTIERE/OVIEDO
}

\author{
Florencio Muñiz Uribe \\ Arquitecto \\ Excmo. Ayuntamiento de Oviedo \\ Javier Rui-Wamba Martija \\ Ingeniero de Caminos, Canales y Puertos \\ ESTEYCO, S. A.
}

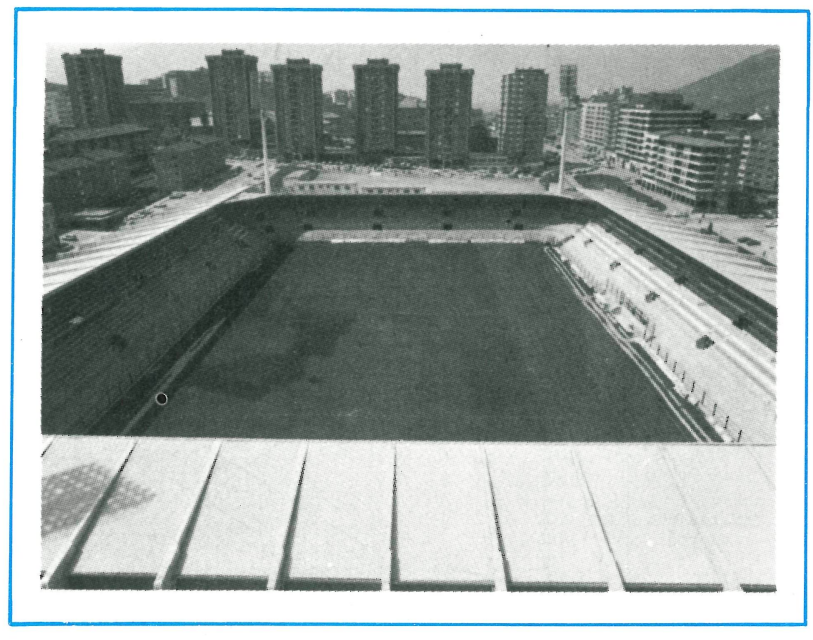

\section{Antecedentes}

El Estadio Municipal Carlos Tartiere, cuando fue inaugurado en 1932 con el nombre de Estadio de Buenavista, disponía de la tribuna de Sánchez del Río, situada en el lado Norte y destinada a espectadores sentados. Enfrentado a ella se había construido un graderío descubierto para espectadores de pie $y$, tras las porterías, existían unas gradas en tierra.

En años sucesivos se ejecutaron diversas obras parciales entre las que destacaron la cobertura del graderío Sur, mediante una estructura metálica y la construcción de una nueva Tribuna cubierta de hormigón, para espectadores de pie en el lado Oeste.

Este mosaico de construcciones heterogéneas, en las que el tiempo fue dejando su huella, fue conformando la configuración más reciente del Estadio, cuyo carácter continuaba marcado fundamentalmente por la más antigua Tribuna Sánchez del Río.

La elección de Oviedo como una de las Sedes del Mundial 82 requería la ejecución de importantes obras y ofreció la ocasión para abordar la modernización de la más popular de las instalaciones deportivas de la ciudad.

\section{Bases de partida}

Dada la situación de las instalaciones del Estadio, era patente que solamente podia ser aprovechable 


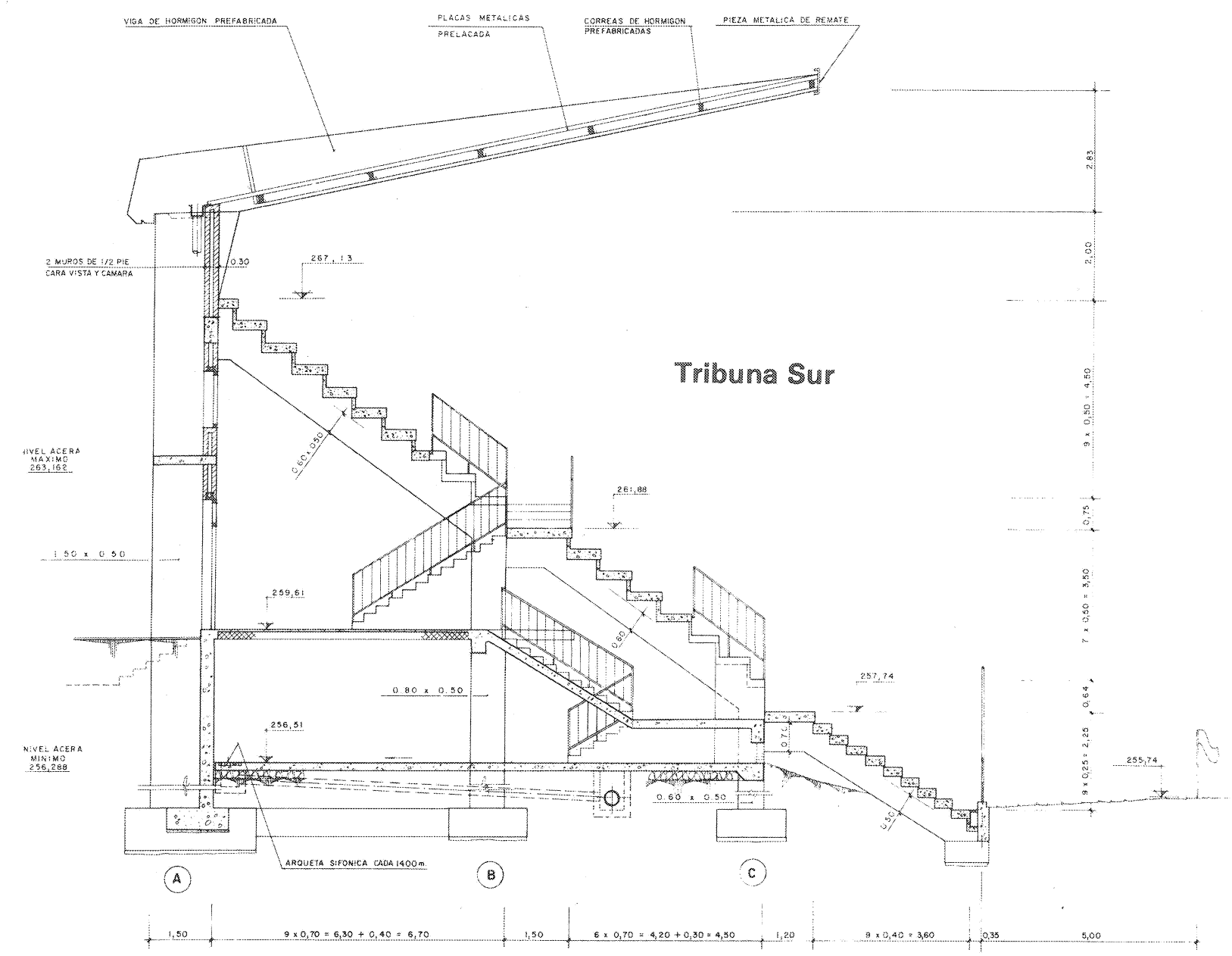

Fig. $1-a$

la antigua Tribuna Sánchez del Rio, unica que disponia de plazas de asiento y de locales para vestuarios y servicios diversos. Era necesario de moler el resto de graderios y tribunas del Estadio para construir los nuevos graderios, aprovechando al máximo el escaso espacio disponible. Con el tiempo, en efecto, el crecimiento de la cludad ha. bia integrado al Estadio dentro de la trama urba na. Su ubicación estaba delimitada por cuatro cam lles, lo que anulaba prácticamente cualquier posibllidad de ampliación. Las lógicas exigencias ur. banisticas limitaban también la altura máxima de las cubiertas de los nuevos graderios.

Con estos datos de partida se abordó la remode. lación del Estadio, incluyéndose también en el proyecto la ejecución de un césped enteramente nuevo, por cuanto el existente no reunia las condiciones necesarias.

\section{Concepción y descripción general de las obras}

La idea directriz en el diseño de las nuevas tribunas consistió en mantener el carácter del anterior
Estadio, en el que destacaba fundamentalmente la solución estructural de la Tribuna Sánchez del Rio, que estaba constituida por una serie de pórticos separados $3,50 \mathrm{~m}$. El elemento más potente de estos pórticos era un pllar apantallado que sa bresalia del cerramiento exterior de la Tribuna. De la cabeza de este pilar arrancaba una viga de canto variable con un tacón inferior formando la cam beza de compresión de la ménsula. En este tacón se recogia la cubierta abovedada de fibrocemento. su ancho era superior al del pllar apantallado y los esfuerzos de compresión que se canalizaban a través de él se recogian en una potente viga cup vada que los conducia a los pilares apantallados y que servia de arriostramiento transversal a los póp. ticos. Una viga inclinada que permitía la creación del graderio y un entramado convencional de vigas y soportes de hormigón, completaban el pórtico tipo.

La solución adoptada para las nuevas tribunas fue análoga. Además de las razones anteriormente apuntadas, el escaso espacio disponible en planta justificaba la creación de pórticos con unas costim llas constituidas por las vigas de cubierta y sus 


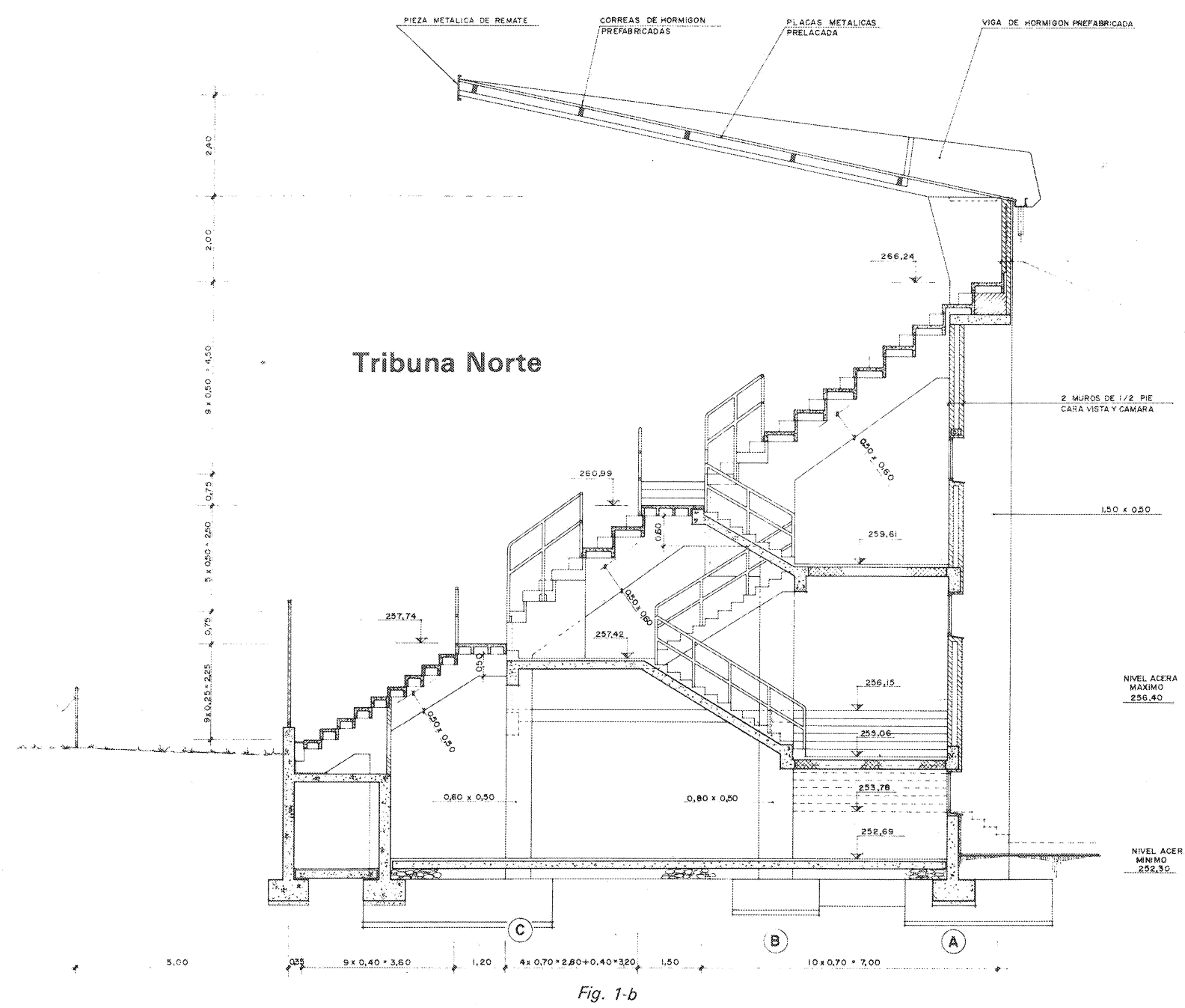

soportes, envolviendo el espacio útil disponible para, asi, aprovecharlo al máximo. En la figura la se representa la geometria de un pótico tipo completo, correspondiente a la Tribuna Sur. Se puede observar el pilar apantallado de 0,50 × 1,50 metros que queda visto en fachada; la viga de cubierta con un talón inferior, en el que apoyan las correas que sujetan el material de cobertura; la viga inclinada que recoge las gradas prefabrica. das y el entramado interior de vigas y pilares para la creación de los espacios destinados a circula ciones, estancias de espectadores y servicios dim versos.

Las necesidades de espacio y la posición elevada de las calles, en relación con el nivel del terreno de juego, justificaron la creación de un sótano, 10 que exigió la construcción de un muro de contenm ción de tierras. Este muro se conectó con los pim lares apantallados que hicieron, a efectos resistentes, de contrafuertes.

En la misma figura $1 \mathrm{~b}$ se ha representado, también, el pórtico tipo correspondiente a la Tribuna Norte y que se ha construido en el lugar que ocupaba la antigua Tribuna Sánchez del Río. Al iniciarse, en efecto, las obras de modernización de esta Tribuna se puso de manifiesto que la estructura, tras cincuenta años de vida, estaba dañada, en particular en las zonas que habian estado en contacto con el terreno, por lo que fue necesario demolerla. El pórtico tipo de la nueva Tribuna era de una concepción idéntica al pórtico de la Tribuna Sur, aunque con geometría diferente.

Pórticos análogos se utilizaron, asimismo, para las Gradas Este y Oeste, resultando una configum ración del Estadio que se puede apreciar en la figura 2.

Las Gradas Este y Oeste están destinadas a espectadores de pie. El graderio dispone de dos pam sillos horizontales de circulación de $1,20 \mathrm{~m}$ de ancho, a los que se accede por un conjunto de 10 vomitorios de $3,00 \mathrm{~m}$ de anchura cada uno. La viga de cubierta vuela desde el soporte $10,80 \mathrm{~m}$ y cubre la grada hasta la proyección del pasillo in ferior. 


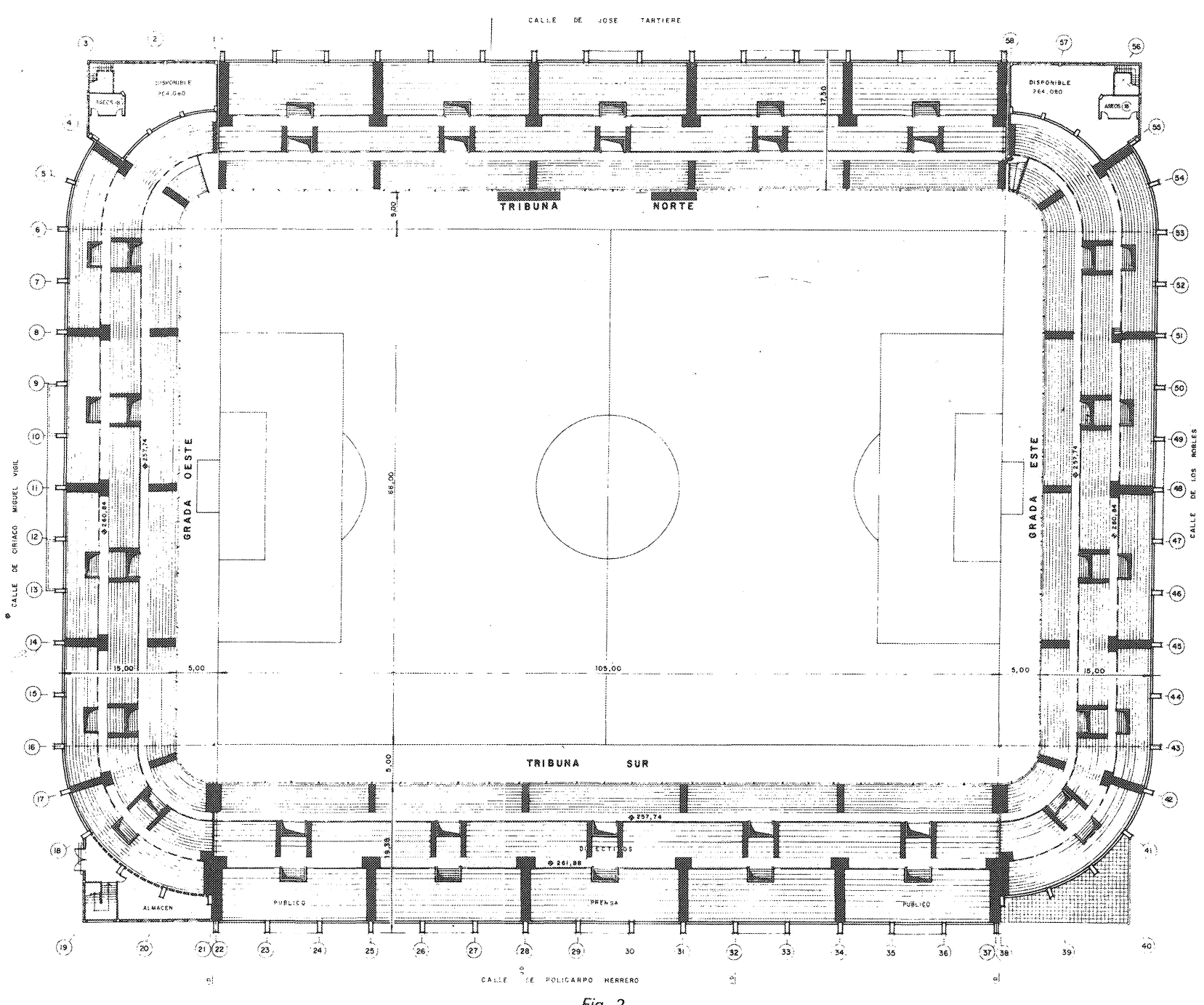

Fig. 2

La Tribuna Sur está proyectada para albergar espectadores de pie y sentados. El graderio tiene una profundidad de $17,50 \mathrm{~m}$. A través de cinco vomitorios de $3,00 \mathrm{~m}$ de ancho se accede a las gradas inferiores, destinadas a espectadores de pie que disponen de un pasillo horizontal de distribucion de $1,20 \mathrm{~m}$ de ancho. Cinco nuevos vomitorios y un pasillo central de $1,50 \mathrm{~m}$ facilita el acceso al resto de las localidades destinadas a espectadores sentados, que quedan protegidos por una cubierta con un vuelo libre de $13,90 \mathrm{~m}$.

Las circulaciones de espectadores en un plano vertical se han representado en los esquemas de la figura 3.

En el encuentro de la Tribuna Norte con las Tribunas Este y Oeste, se han dispuesto dos edificaciones constituidas por cinco niveles de forjam do en el caso del Edificio Noreste, y tres en el caso del Edificio Sureste, que permiten, además, resolver la transición entre las tribunas con dife- rente altura de cubierta. También en las otras dos esquinas del Estadio se han dispuesto unos 10 cales bajos, adosados a los graderios. Las facham das de estos núcleos se han resuelto con ladrillo cerámico cara vista e idéntico tratamiento han recibido los cerramientos exteriores de las Tribunas, en los que han quedado, además, vistos los pilam res apantallados de hormigón de la estructura.

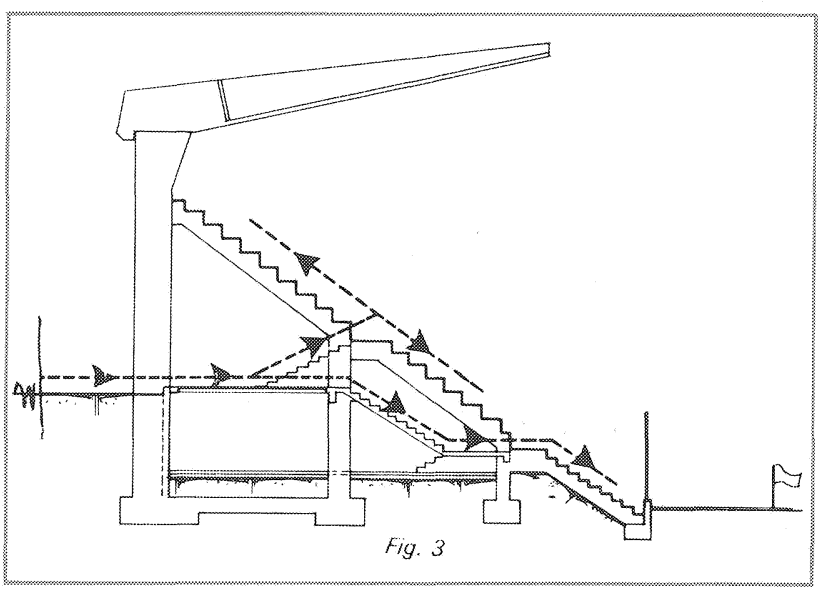


Con las dimensiones de los graderios construidos, el número y distribución de localidades con que oficialmente contará el Estadio serán las si. guientes:

\begin{tabular}{|c|c|c|c|}
\hline & $\begin{array}{l}\text { Espectadores } \\
\text { sentados }\end{array}$ & $\begin{array}{c}\text { Espectadotes } \\
\text { de pie }\end{array}$ & TOTAL \\
\hline Tribuna Norte...... & 2.640 & 1.890 & 4.530 \\
\hline Tribuna Sur.......... & 3.010 & 2.100 & 5.110 \\
\hline Tribuna Este........ & - & 6.273 & 6.273 \\
\hline Tribuna Oeste...... & - & 6.273 & 6.273 \\
\hline TOTALES ... & 5.650 & 16.536 & 22.186 \\
\hline
\end{tabular}

Bajo los graderios y en las edificaciones adosadas en las esquinas del Estadio, se han creado espacios para oficinas, vestuarios, taquillas, bares, servicios, policia, sanidad, etc., asi como para los locales técnicos y de servicios necesarios durante la celebración del Mundial-82.

Entre las obras también ejecutadas, destacan las del césped, que cuenta con un sistema de drenaje enteramente nuevo y un sistema de aspersores de funcionamiento automático.

Finalmente, se ha dotado al Estadio de cuatro to rres de iluminación de 40 metros de altura, situadas en las cuatro esquinas exteriores del Estadio, en las que se sitúan un total de 336 proyectores halogenuros de 1.500 watios que garantizan el nivel de lluminación exigido para las retransmisiones televisadas en color.

\section{Descripción de la estructura}

Al tratar de las caracteristicas generales de la obra ya ha quedado esbozada la descripción de la estructura, que en esencia está constituida por una serie de pórticos transversales separados 6,80 metros en el caso de las Gradas Este y Oeste, y $7,00 \mathrm{~m}$ en las Tribunas Norte y Sur, y una serie de elementos, vigas, forjados cerámicos y gradas prefabricadas entre ellos.

La cimentación de los pórticos está constituida por unas zapatas que apoyan sobre una capa de caliza margosa muy resistente que, dada la pendiente natural del terreno, en los puntos más altos de éste, hacia el lado Oeste, ha aflorado en superficie y en los puntos más bajos se oculta bajo un manto de relleno de unos tres metros de espesor.

Los pilares y vigas del pórtico tienen un espesor constante de $0,50 \mathrm{~m}$. La otra dimensión, en el
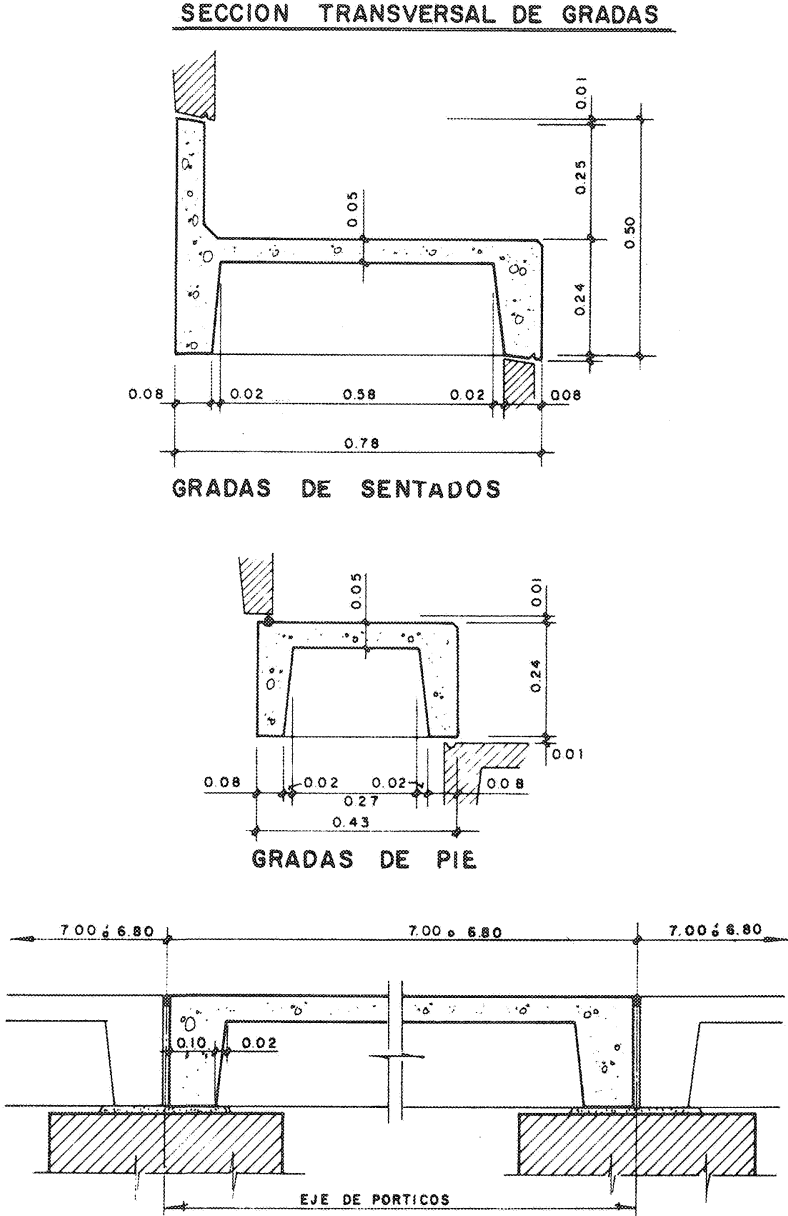

SECCION LONGITUDINAL GRADAS

Fig. 4

sentido del pórtico, del pilar exterior es de 1,50 metros. Sobre este pilar se apoya lateralmente el muro de hormigón armado que soporta el empuje de las tierras y permite la creación del sótano. El muro tiene altura variable, adaptándose al nivel variable de las calles perimetrales.

Las vigas horizontales de los porticos reciben el forjado cerámico transversal. Se han dispuesto otras vigas en sentido perpendicular a los porticos para asegurar su estabilidad transversal $y$, en algunos casos, para servir de apoyo a las losas de escaleras y a los cerramientos.

Se han proyectado especificamente para este Estadio dos tipos de grada, para espectadores de pie y sentados. La geometria de las gradas tipo está representada en la figura 4 . Ambos tipos se han construido de hormigón armado, en un taller situado a unos $15 \mathrm{~km}$ de la obra, y se han colocado en obra por medio de grúas sobre neumáticos, apoyándolas directamente sobre las vigas inclinadas que se habian hormigonado con la forma de los peldaños. 


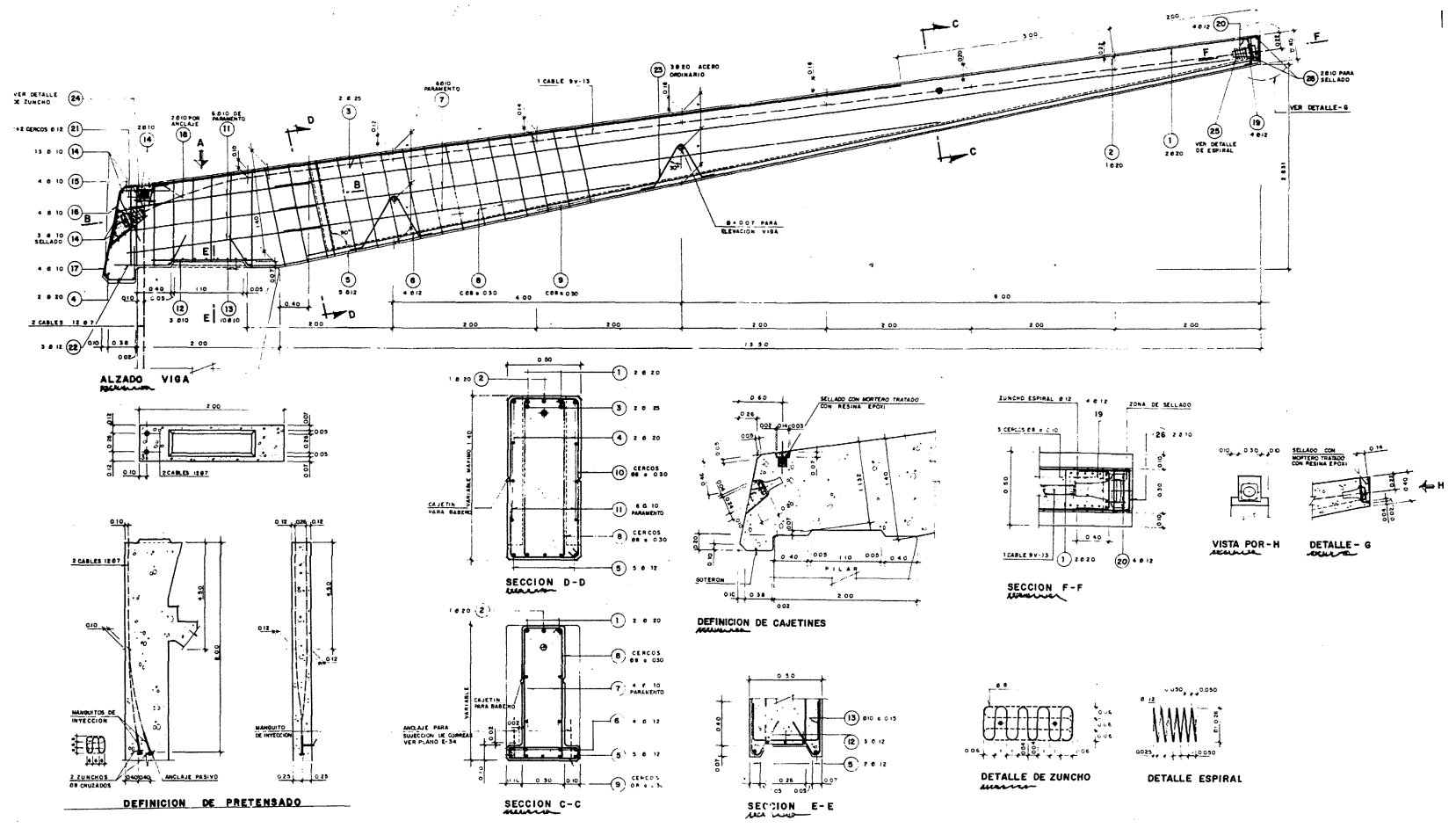

Fig. 5

El aspecto más interesante de la estructura proyectada está en la concepción de la viga de cubierta y en su conexión con el pilar exterior del pórtico. La geometria de la viga y los detalles de armado de la correspondiente a la Tribuna Sur, están representados en la figura 5 . La sección característica de la viga es rectangular, de $30 \mathrm{~cm}$ de ancho y altura variable; dispone en su parte inferior de dos talones de $10 \times 10 \mathrm{~cm}$, sobre los que apoyan las correas de hormigón armado que soportan el material de cobertura del Estadio.

La viga es prefabricada y está armada con un cable de postensado constituido por 9 torones de $1 / 2$ pulgada, de acero superestabilizado con límite de rotura superior a $19.000 \mathrm{~kg} / \mathrm{cm}^{2}$. Además, dispone de la armadura pasiva necesaria. Se trata de un caso en el que hemos aplicado el concepto del pretensado parcial.

Definiendo el grado de pretensado por la relación:

Momento de descompresión después de pérdidas Momento para las máximas cargas de servicio

nos encontramos, en la sección más desfavorable, un valor de 0,52 que crece rápidamente hasta hacerse igual a la unidad.
En estas condiciones, el incremento de la tensión del acero pretensado para cargas en servicio, no excede de $1.500 \mathrm{~kg} / \mathrm{cm}^{2}$, limite aceptado por la Norma suiza, por ejemplo.

La abertura estimada de las fisuras para las máximas cargas en servicio es del orden de $0,10 \mathrm{~mm}$ perfectamente admisibles; las fisuras son de tal naturaleza que, de llegar a producirse, se cerrarán cuando se descargue la ménsula.

La conexión de esta viga prefabricada. con el pilar apantallado ejecutado en obra, se realiza por medio de una técnica análoga a la de las juntas conjugadas, utilizada en la construcción de puentes por voladizos sucesivos con dovelas prefabricadas. Al hormigonar el soporte apantallado se dejan dos cables $12 \varnothing 7$ con anclajes ciegos, según puede observarse en la figura 5 . El soporte se hormigona hasta aproximadamente $30 \mathrm{~cm}$ de su coronación. Se coloca entonces un encofrado muy rigido en cabeza que se nivela y orienta cuidadosamente, y se procede al hormigonado del soporte. Previamente y con el mismo encofrado se han hormigonado unos dados que reproducen exactamente la superficie del soporte. Estos dados se incorporan al encofrado de fondo de la viga prefabricada, de manera que al hormigonar ésta la superficie de apoyo reproduce perfectamente la forma invertida de la cabeza del soporte. Para la conexión del soporte y viga basta enfilar los dos cables vertica- 
les por los agujeros previstos al efecto en la viga. Sobre las superficies de contacto se ha aplicado un tratamiento de resina epoxi. Encajada la viga sobre el soporte, se procede al tesado de los cables, pudiendo entonces liberarse la grúa que, hasta ese momento, ha debido sujetar la viga. Más adelante se procede a la inyección de las vainas que van provistas de purgas en su parte inferior.

Las operaciones descritas se realizaron con gran sencillez y se alcanzó un ritmo de ocho vigas colocadas con una grúa en una jornada normal de trabajo.

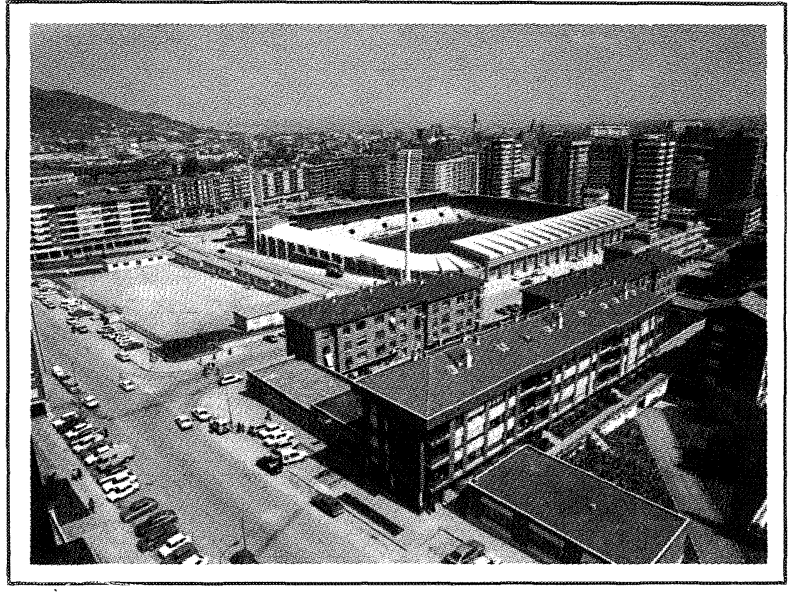

\section{publicaciones del i.e.t.c.c.}

\section{las resinas epoxi en la construcción}

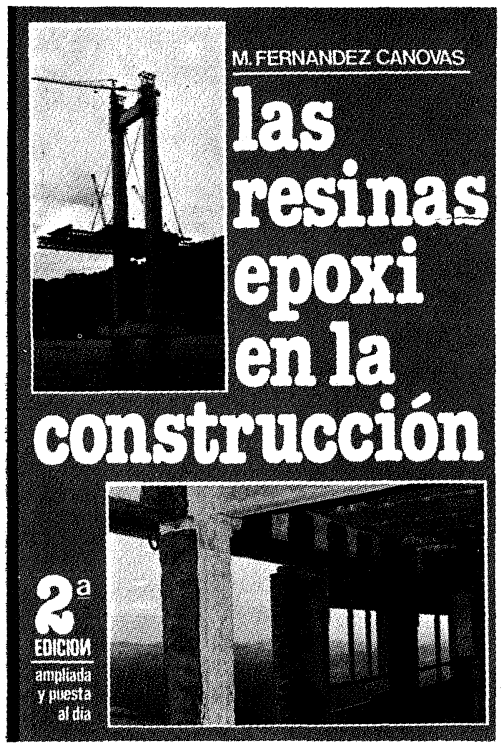

Manuel Fernández Cánovas

Dr. Ingeniero de Construcción

Este libro, el primero en lengua castellana sobre resinas epoxi aplicadas a la construcción, está dirigido a arquitectos, ingenieros, constructores y aplicadores. En él, sobre una reducida base teórica imprescindible, se asienta toda una extensa gama de aplicaciones de gran interés.

El autor trabaja desde hace muchos años en el campo de la investigación, especialmente en el estudio de refuerzos y reparaciones estructurales realizados con resinas epoxi.

Con un lenguaje sencillo se tocan todos los problemas que pueden presentarse en la construcción y en los que la solución puede radicar en el correcto empleo de las resinas epoxi.

Se estudian los componentes de las formulaciones epoxi, sus propiedades físicas y químicas, y aplicaciones, deteniéndose, detalladamente, en las siguientes:

Unión de hormigón fresco a hormigón endurecido. - Unión de hormigones entre si.-Inyecciones de fisuras y grietas. - Unión de acero a hormigón. - Barnices y pinturas. - Las combinaciones brea-epoxi. - Revestimientos de depositos alimenticios. - Sellado de superficies cerámicas. - Protección de tubos. - Los suelos epoxi en sus diferentes variantes. - Terrazo epoxi. - Reparación de baches. - Reparación de desperfectos en estructuras. - Repación de carreteras de hormigón. - Juntas elásticas. - Guardacantos de tableros de puennes. - R prerzos de pil vigas, forjados y zapatas, etc. - Consolidación de suelos. - Anclajes. - Protección de aceros en pretensado.

Se termina con unos capitulos dedicados a la limpieza y preparación de las superficies según los materiales a unir:

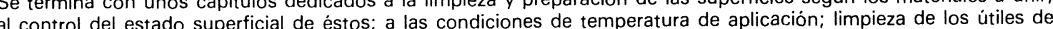
a métodos de ensayo de sistemas y aplicaciones epoxidicas.

Un volumen encuadernado en cartoné plastificado con lomo de tela, de $17 \times 24 \mathrm{~cm}$, compuesto de 334 páginas y 158 figuras y fotografias.

Madrid, 1981.

Precios: España, 1.700 ptas.; extranjero, \$ USA 34.00

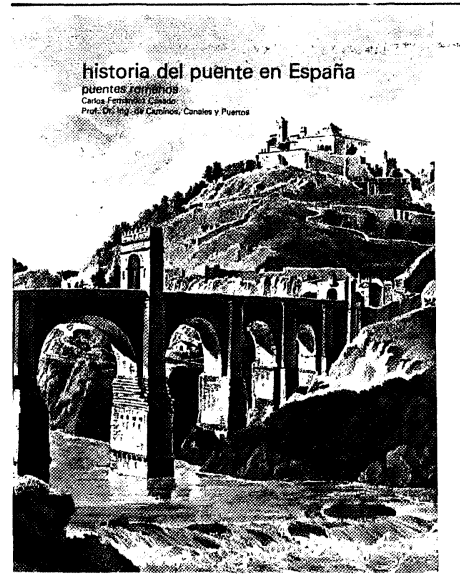

\section{historia del puente en España} puentes romanos

\section{Carlos Fernández Casado}

Prof. Dr. Ing. de Caminos

Canales y Puertos

Unos apéndices añadidos a los doce articulos originales informan sobre las variaciones experimentadas por algunos puentes más importantes como la del traslado de las ruinas mejor conservadas del puente de Alconétar, que corrió el peligro de quedar sumergido en el embalse de Alcántara, y la reparación de la cimen de una de las pilas centrales del puente de este mismo nombre que fue detectada, al quedar durante unos dias cortado el curso del Tajo, para realizar el montaje de los desagües de fondo correspondientes a la presa del citado embalse.

Un volumen encuadernado en cuché, a dos colores, de $21 \times 27,5 \mathrm{~cm}$, compuesto de 554 páginas, 105 grabados, 14 dibujos, 753 fotos blanco y negro, 24 fotos color y 110 dibujos de línea.

Madrid, 1981

Precios: España, 3.000 ptas.; extranjero, \$ USA 60

NOTA:

Debido al actual cambio de la peseta, con respecto al \$USA, todos los pedidos de publicaciones del IETcc (sin incluir revistas) que se efectúen a librerías en el extranjero, e incluso directos, obtendrán una bonificación del $30 \%$ sobre los precios marcados en dólares. Este descuento será aplicado por los vendedores - hasta 